\title{
Numerical Optimalization of the Electric Bus Radiator in Terms of Noise Emissions and Energy Consumption
}

\author{
Artur Głogoza ${ }^{1}$, Anna Janicka ${ }^{2, *}$, Radosław Włostowski ${ }^{2}$ and Maciej Zawiślak ${ }^{2,}$ \\ 1 OE Industry Sp. z o.o., ul. Marcika 6, 30-443 Kraków, Polska, e-mail: a.glogoza@oeindustry.com \\ 2 Wrocław University of Science and Technology, Division of Automotive Engineering, ul. Wyb. \\ Wyspiańskiego 27, Wrocław, Polska, e-mail: anna.janicka@pwr.edu.pl \\ * Correspondence: anna.janicka@pwr.edu.pl; Tel.: +48 713477918
}

\begin{abstract}
The dynamic development of electromobility poses challenges to designers regarding not only the efficiency of energy transformation but also the battery life, which is influenced by the stability of its operating temperature. Designing cooling systems is connected not only with the optimization of energy management but also with other environmental parameters, such as noise emission. The paper presents the numerical optimization of an innovative radiator for use in electric buses in terms of energy consumption and noise emission. The results of the numerical studies were verified in laboratory and field conditions, showing a very good convergence of the model with the results of the experiments.
\end{abstract}

Keywords: automotive engineering, electric bus, CFD, numerical fluid mechanics, electromobility, noise, eco-design

\section{Introduction}

The multi-faceted eco-design of motor vehicles concerns not only reduction and optimization of energy and material consumption as well as pollutant emissions, but also aspects related to vibration and noise protection for both vehicle users and the external environment. The structure of the motor vehicle market is changing dynamically. In addition to the challenges common to all types of vehicles, such as aerodynamics and body morphology, eco-design varies greatly depending on the type of drive used.

In the case of conventional vehicles, equipped with internal combustion engines (ICE), designing in accordance with the principles of sustainable development currently focuses mainly on rightsizing trends, improving the efficiency of fuel combustion and its composition as well as the efficiency of exhaust gas treatment systems. An interesting approach to improving the efficiency of ICE is demonstrated in the work of Sroka and Sadlak [1], where the authors present study results showing that the use of an active combustion chamber (based on thermal barriers) can improve the effective efficiency of the engine from 10 to $20 \%$.

However, the dynamic development of electromobility observed in the last decade poses further challenges for designers. In addition to the issue of energy transformation efficiency, lifetime, capacity and recycling of batteries, there are also areas of concern identical to the vehicles equipped with a classic drive, such as noise emission. In this case, nevertheless, it does not apply to the drive unit itself, i.e. the electric motor, but to the coexisting systems. The use of an electric motor both as a stand-alone drive and in a hybrid system requires the use of new solutions in the field of cooling systems whose task is to maintain the vehicle's batteries in appropriate thermal conditions.

The thermoregulation systems of batteries for use in electric vehicles are currently the subject of numerous studies related to energy optimization, the type and composition of the coolant, their effectiveness, noise emission and control. Shashank [2] (2018), in his literature review, emphasized the importance of thermal management in electric vehicles and its impact on the life of lithium-ion batteries, which are significantly sensitive to 
temperature. A year later, a similar review paper was published by Kim [3] (2019), demonstrating the advantages and disadvantages of various battery thermal management system (BTMS) solutions and presenting his own solution in this area. The dynamic development of technology and the ever-growing interest in battery cooling are also indicated in a paper published the following year. Mengyao et al. [4] (2020) demonstrated advances in research on electric vehicle cooling technology aimed at eliminating temperature peaks and large temperature gradients. He presented an overview of existing battery thermal management systems, the advantages and disadvantages of cooling systems based on both air and liquid cooling. He defined the trends in their development, such as miniaturization or reduction of relatively high energy demand. The paper also indicated that minimizing the impact on user comfort (mainly in relation to the noise generated by the airflow through the fan and enclosure) is an important research issue.

The problem of research on BTMS was also highlighted by Akinlabi and Solyali [5] (2020), who identified the incorrect temperature distribution in the battery pack (primarily in the significant temperature difference) as the cause of the main problems related to the battery operation. Jing et al [6] (2020) stressed the importance of environmental aspects in the design of vehicle cooling systems and presented the results of a research study aimed at a detailed analysis of the operating medium in terms of environmental aspects. Shen and Gao [7] (2020) focused on the properties of the cooling medium in liquid-cooled battery systems and their impact on cooling efficiency. Another team of researchers has published interesting papers on the possibility of using heat pumps to cool car batteries. Dong et al [8] (2020) and Wang et al [9] (2020) have shown in their experimental studies that such solutions have a high application potential in motor vehicles. Chen et al [10] (2021) confirmed their conclusions by proposing a carbon dioxide-based heat pump for cooling electric vehicle batteries. However, the researchers Qiu and Shi [11] (2020), presenting their theoretical analysis results, lean in their considerations towards thermoelectric cooling.

Numerical fluid mechanics, which is a research tool enabling the modeling of the effects of flow phenomena both for the purposes of analysis and diagnostics of systems, as well as their multi-criteria optimization, has been used since the 1990s as a research method for vehicle design, and in recent years in electric vehicles, in particular in solving problems of aerodynamics, energy management and noise modeling. In Zawiślak's paper [12] (2017), a review of the research conducted so far was made and then a method for designing flow machines and systems using CFD methods on the micro and macro flow scale was proposed and described. Three years later, Ruiqing et al [13] (2020), reviewing the applications of CFD methods in the last decade (2010-2020), conclude that it is not only a tool for the diagnosis and design of flow devices and systems, but also a tool for a better understanding of the physical phenomena occurring in the flow system, indicating numerous possibilities for the use in the latest solutions in non-conventional vehicles (including electric vehicles).

Haowen et al.'s [14] (2017) paper presents the problem of noise distribution in the electric vehicle cabin, taking into account multiple sources. The authors indicate that the use of three-dimensional CFD calculations on the basis of a two-equation $k-\varepsilon$ turbulence model allows for very good consistency of the calculation results with the measurement results. Zhang et al [15] (2017) applied numerical fluid mechanics to optimize the vehicle cooling system by taking into account the geometry of the entire vehicle under operational conditions. The researchers' interest was focused on optimizing the radiator and the cooling drag. Thanks to the use of CFD methods, design recommendations for efficient vehicle cooling have been specified.

Recently, there has been a significant increase of the numericians' interest in the cooling of electric vehicle batteries. Hamidreza et al [16] (2020), using CFD methods, performed a comparative analysis of different hybrid vehicle battery cooling techniques and methods to assess the efficiency of thermal management. Also Benabdelaziz et al [17] (2020) successfully use CFD tools to test battery cooling efficiency with the developed solution in various geometric variants. The result of the execution of their work is an 
improvement in the operation of the cooling system based on proprietary solutions (including heat-pipe [16]), understood as a reduction of the temperature gradient on the battery pack. Yuan et al [18] (2020) identifies numerical and co-numerical modeling of flows based on the latest available computational fluid mechanics tools as the right direction for the design of cooling systems for vehicle components.

\section{2. The research object and purpose}

The object of the research were radiators with an air distribution system in the housing, intended for use in cooling a pack of lithium-ion batteries / fuel cells. The developed solution can be applied in buses with an electric drive, including those with an optional braking resistor and in vehicles with a hydrogen drive. The cooling systems have been designed using the best available technologies in terms of material selection, type and shape of the core cross-section and verified using CFD methods.

The modules were equipped with a set of fans, liquid and air temperature sensors, a wire harness adapted to communication via the CAN 2.0B bus, with a transmission speed of $250 \mathrm{~Kb}$ ps. Dedicated control systems with proprietary software enabling autonomous operation with the lowest possible demand for electricity have been developed and manufactured. The view of the research object - the object of numerical analysis - is shown in Figure 1.

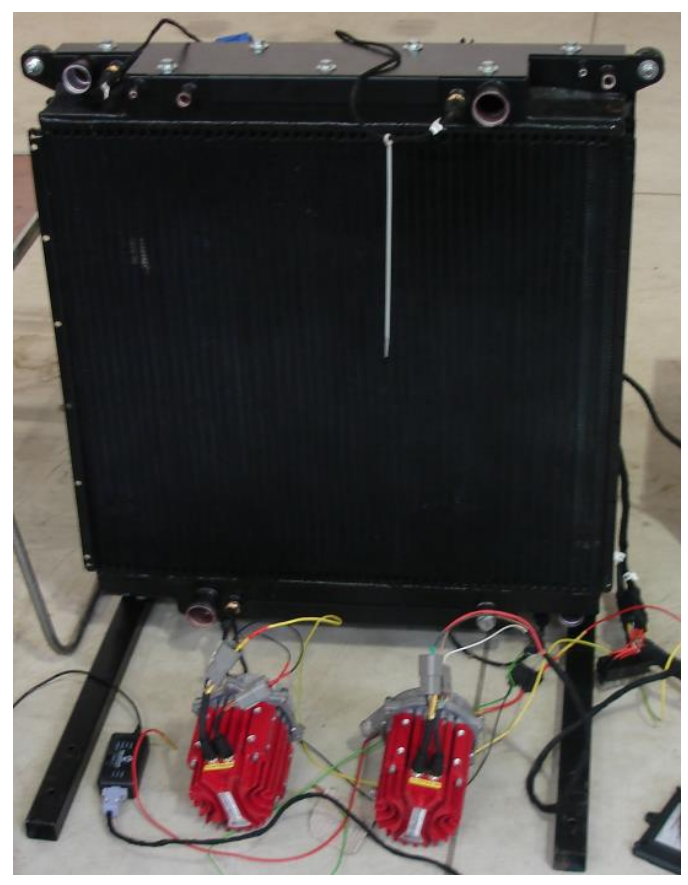

Figure 1. The research object

The aim of the research was numerical optimization of the device for minimizing noise emissions (improving the comfort of bus users) while maintaining the desired high efficiency of cooling the battery pack

\section{The research methods}

Numerical (simulation) tests were performed using the finite volume method (MOS), with the application of numerical fluid mechanics methods. ANSYS-FLUENT software was used. The flow of the cooling medium (air) was modeled using the RANS method. The two-equation $k-\varepsilon$ turbulence model, the heat transfer model and the acoustic model were used. In order to determine the flow velocity boundary conditions, the available characteristics of the fan intended for use in the designed radiator were used. The assumed air temperature was $298 \mathrm{~K}$ and the assumed fluid temperature in the radiator was $373 \mathrm{~K}$. 
Measurements in laboratory conditions were carried out at the Division of Automotive Engineering of Wrocław University of Science and Technology. A test stand was built, on which the supplied system was installed, consisting of a radiator with connecting wires, a circulating pump mounted between the buffer tank and the radiator (the coolant is sucked from the buffer tank and then pumped into the radiator), a flow meter mounted on the return wire from the radiator (in front of the buffer tank). A diagram of the stand is shown in Figure 2.

The buffer tank filled with coolant (water and glycol mixture, 5\% vol. glycol), with a total volume of $65 \mathrm{dm} 3$, was equipped with three heating units with thermostatic systems with $18 \mathrm{~kW}$ of electric power. The system has 4 temperature sensors (PT-100); 2 sensors measuring the temperature of the coolant (coolant inlet and outlet from the radiator) and 2 sensors measuring the air temperature (air in front of the radiator and air behind the radiator at a distance of $1 \mathrm{~m}$ from the radiator. Electrical value measurements were made using a voltmeter, a current clump and an oscilloscope with recording software. Due to the type of control system, the current was measured by measuring the battery charging current.

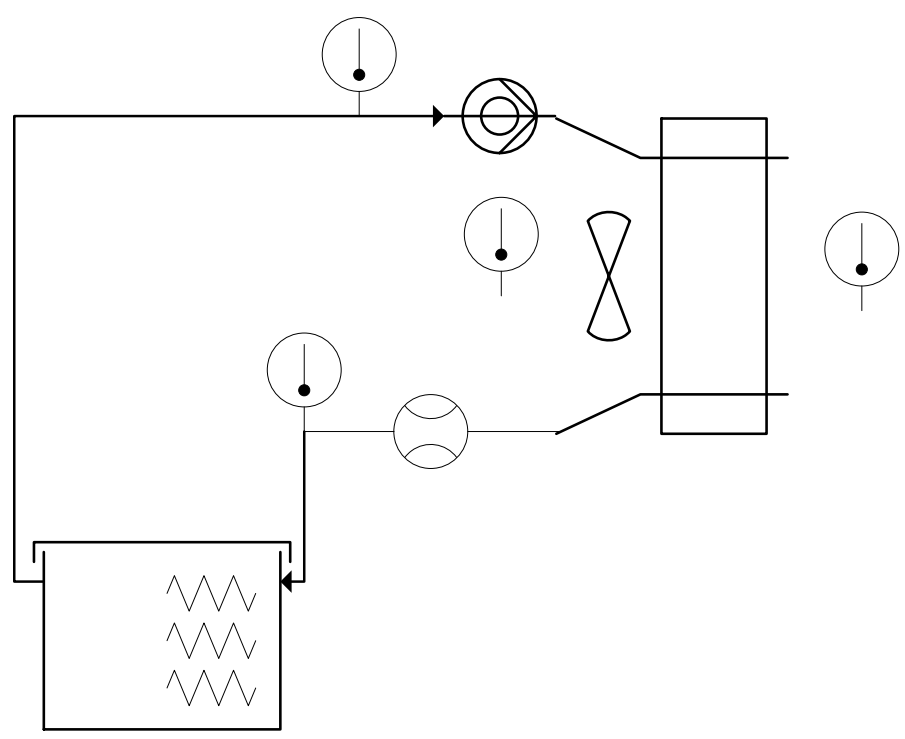

Figure 2. A schematic diagram of the test stand

The characteristics of the coolant flow were determined depending on the load, expressed as a percentage of the load defined by the software. In addition, the characteristics of the current consumption of the circulation pump and cooling fans were determined, depending on the load defined as above. Additionally, oscilloscope waveforms of the current values at the device start-up were recorded. The maximum instantaneous values of current during start-up (at a nominal voltage of $27.1 \mathrm{~V}$ ) did not exceed the nominal values of the devices.

Measurements in real (field) conditions were made at the Military Institute of Armoured and Automotive Technology on specially constructed measuring stands, according to a specially developed method (test certificate 41/LPE/2020) using a digital multimeter with instrumentation and a set of power batteries (device power) and a type 2250 sound level meter (noise level).

\section{Results}

Figure 3 shows a discrete model (a numerical grid based on tetra elements) of the vehicle in which the analyzed radiator is planned to be installed. 

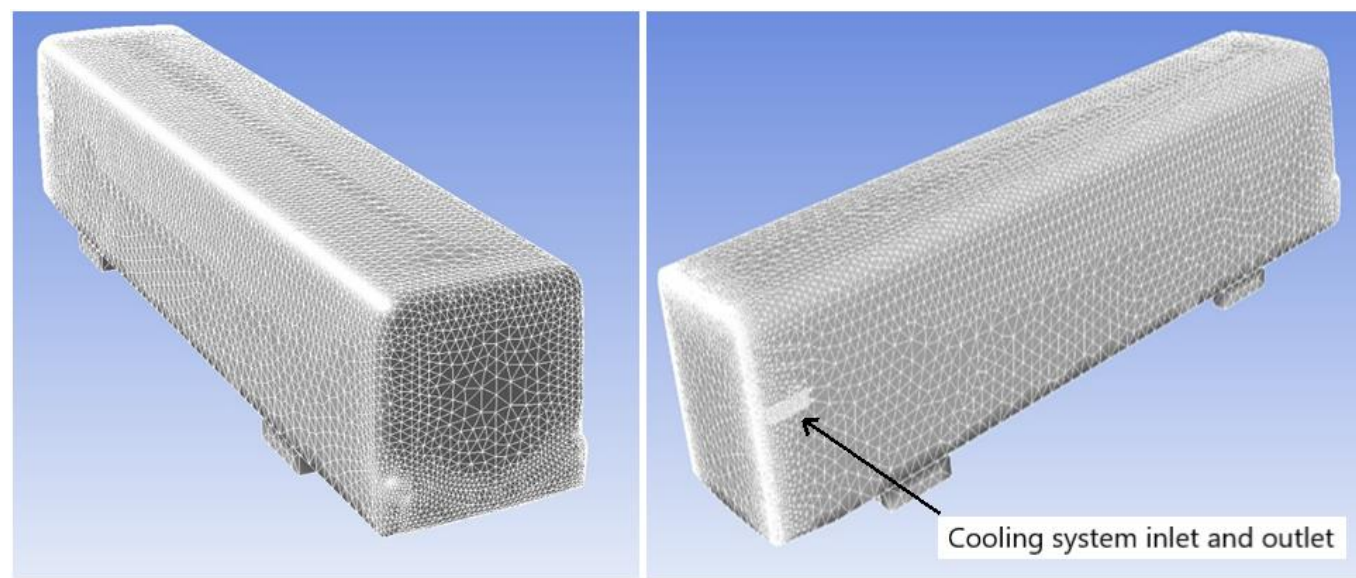

Figure 3. A discrete model of an electric vehicle (bus)

A simulation of airflow around the vehicle was performed in order to determine whether there are no adverse flow phenomena at the cooling system attachment point (shown in Figure 3).

Figure 4 presents the results of calculations showing the behavior of the streamlines during the flow under the given speed conditions $(90 \mathrm{~km} / \mathrm{h})$.
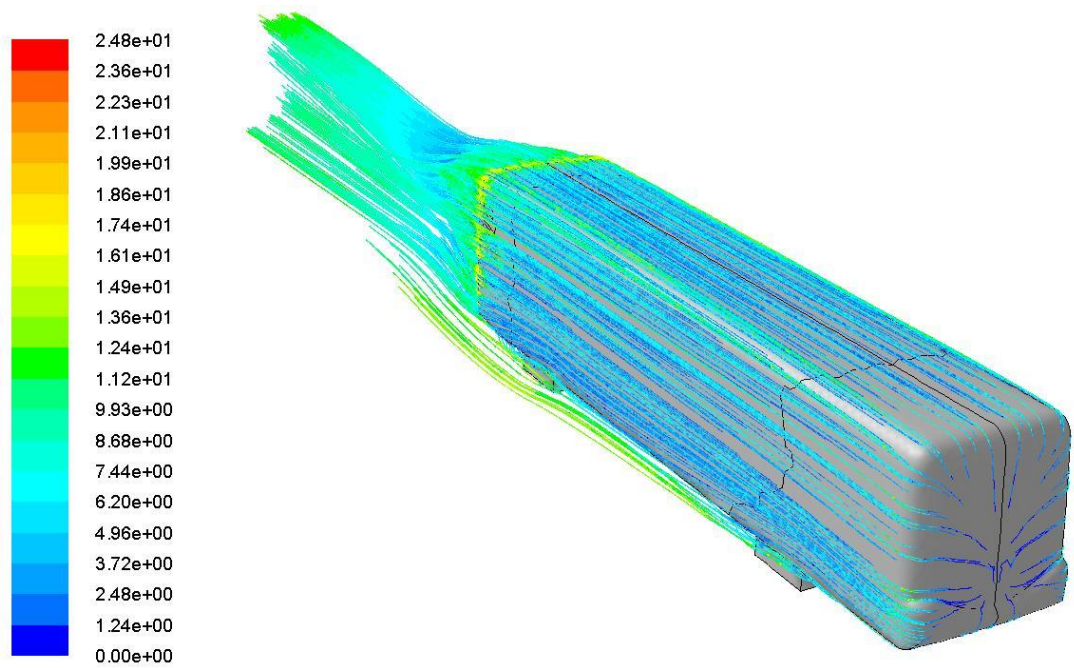

Figure 4. Streamlines - view of the bus from the front of the vehicle on the side of radiator mount-

$$
\text { ing }
$$

Streamlines - radiator inlet grilles and streamlines with operating fans are shown in Figure 5.

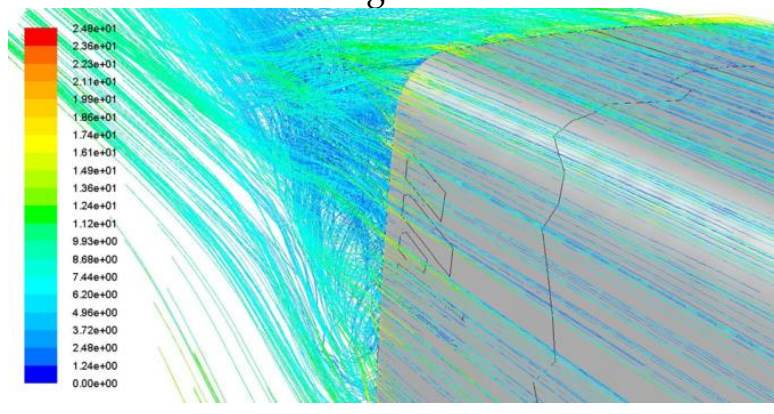

(a)

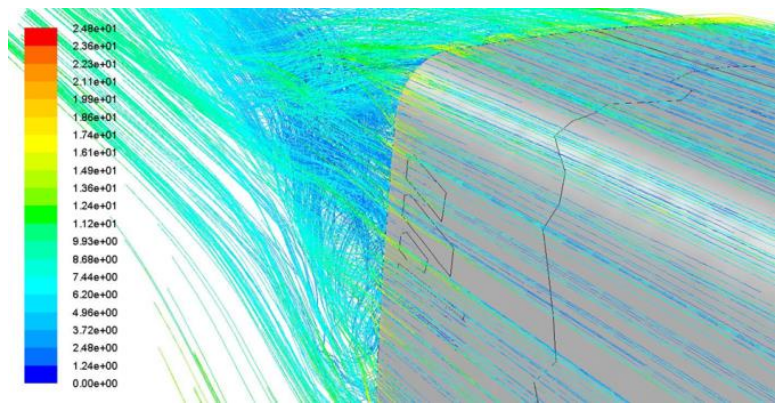

(b) 
Figure 5. Streamlines - radiator inlet grilles and streamlines with operating fans: view of the inlet grilles: a) when the vehicle is moving without the cooling system on, b) when the vehicle is moving with the cooling system on.

180

181

Despite the correct flow of air around the vehicle (Figure 4), it was found that when the radiator fans were switched on, the flow into and out of the radiator box has swirl zones and dead zones of the flow. In order to improve the flow condition (air inlet and outlet from the system), an analysis of the flow inside the radiator attachment point with operating fans (inside the radiator housing) was performed. The calculation results are presented in Figure 6.

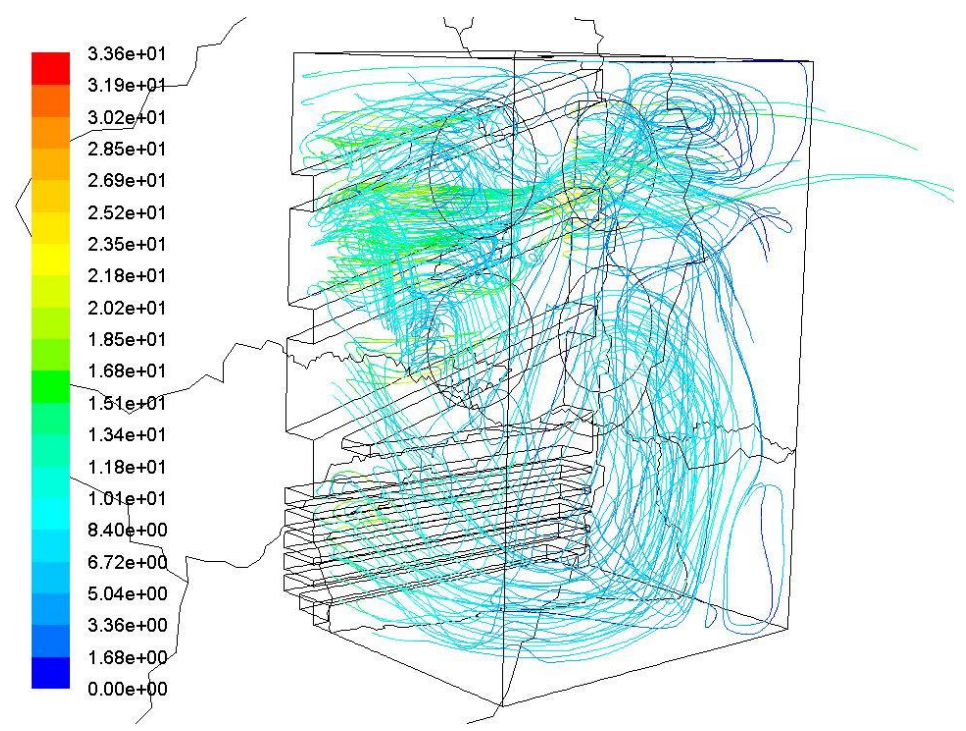

Figure 6. Streamlines inside the radiator box

Observation of the streamlines indicates the need for precise direction the stream flow through the use of guide vanes.

The simulation results showed dead fields of the flow, i.e. a decrease in the efficiency of the radiators and noise levels above $72 \mathrm{~dB}$. In addition, the position of the fans was found to be correct (no stream detachment and no flow swirl). However, flow-dead zones were observed during the operation of the fans. It was decided to redesign the fan-housing box. Four geometric models were selected for analysis (Figure 7). They were modeled at the operating point corresponding to $50 \%$ of the fan load in the following geometry variants:

(a) without a guide vane,

(b) with one guide vane,

(c) with two guide vanes,

(d) with stream separation.

Figure 8 shows the simulation results in the form of a determined distribution of acoustic pressure fields

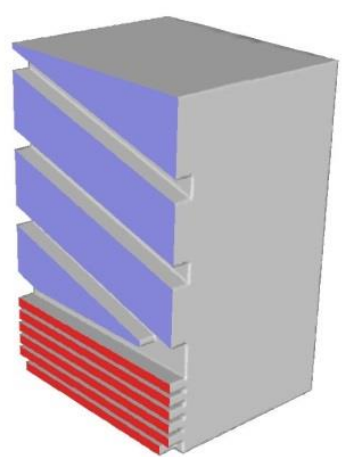

(a)

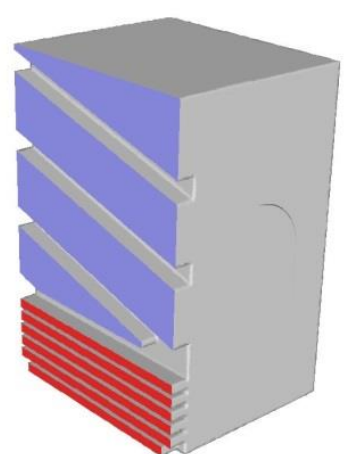

(b)
190 


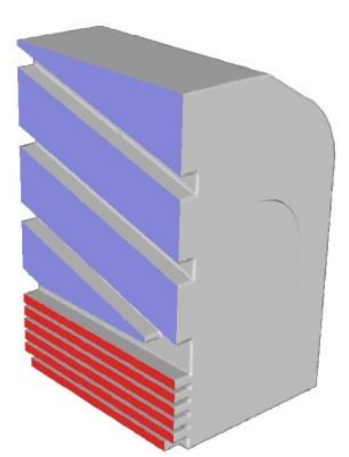

(c)

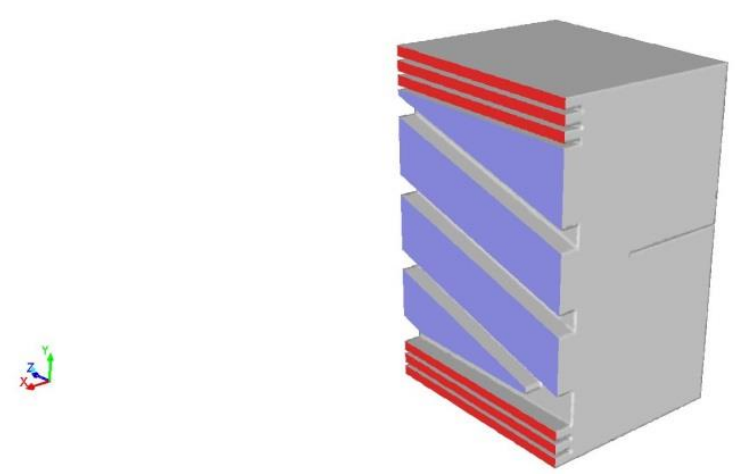

(d)

Figure 8. Acoustic pressure fields [dB]: (a) without guide vanes, (b) with one stream guide vane, (c) with two stream guide vanes, (d) with stream separation.

\section{$x^{2}$}

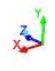

(b)
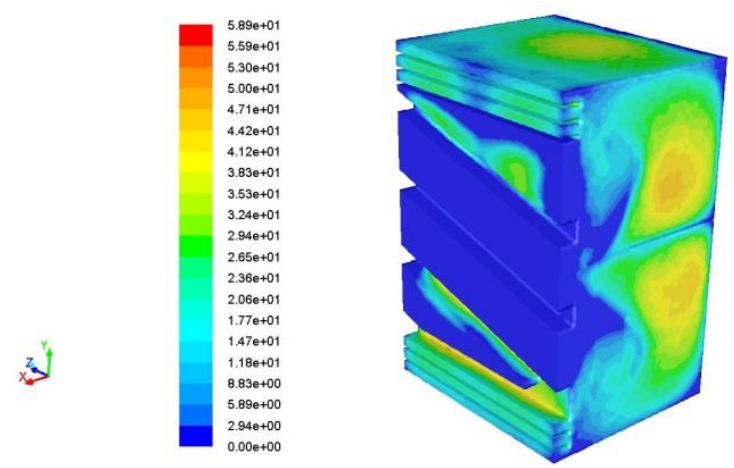

(d)

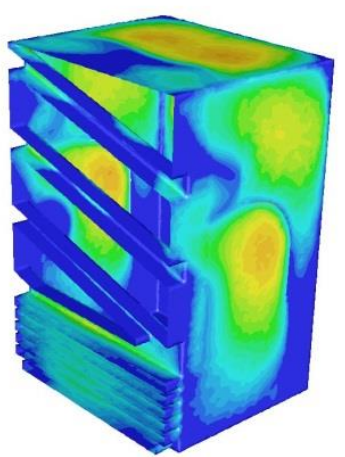

$x^{2}+5$

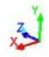

205

(c)
207

208

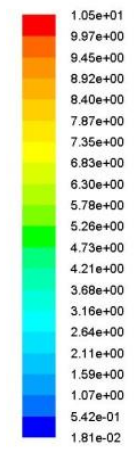

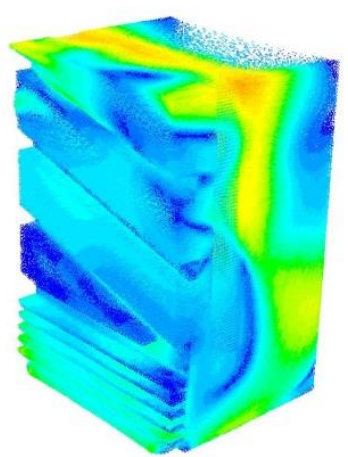

(a)

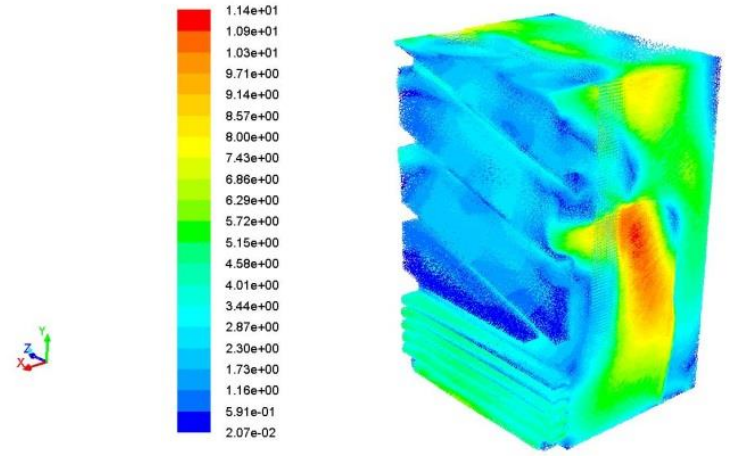

(b) 


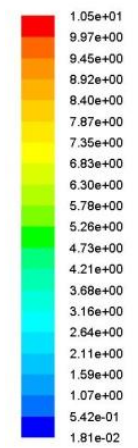

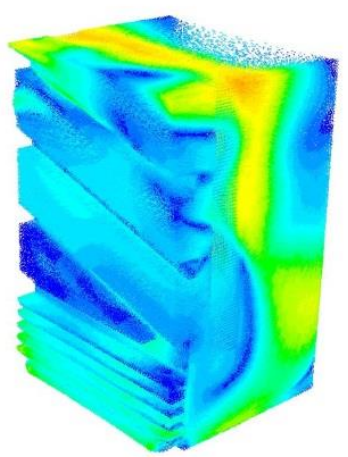

(c)

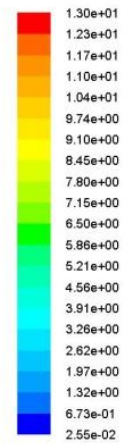

$2.55 e-02$

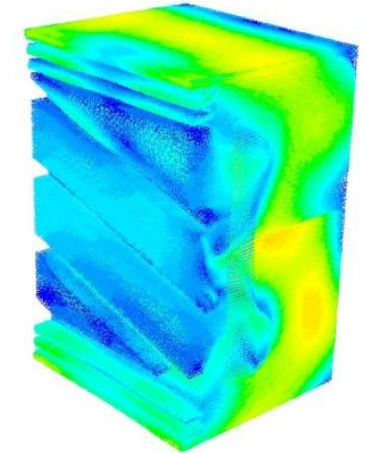

(d)

Figure 9. Velocity vector fields [m/s] (a) without guide vanes, (b) with one stream guide vane, (c) with two stream guide vanes, (d) with stream separation
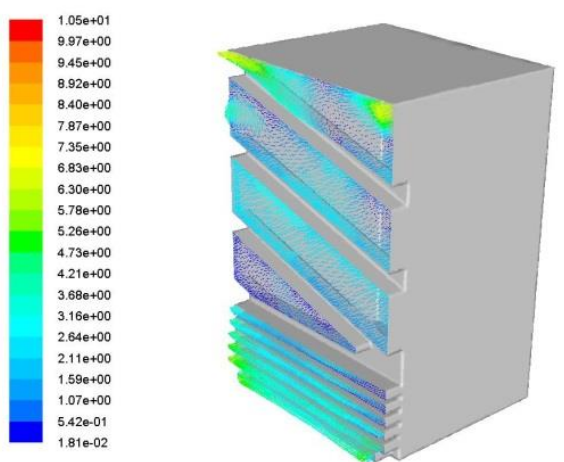

(a)
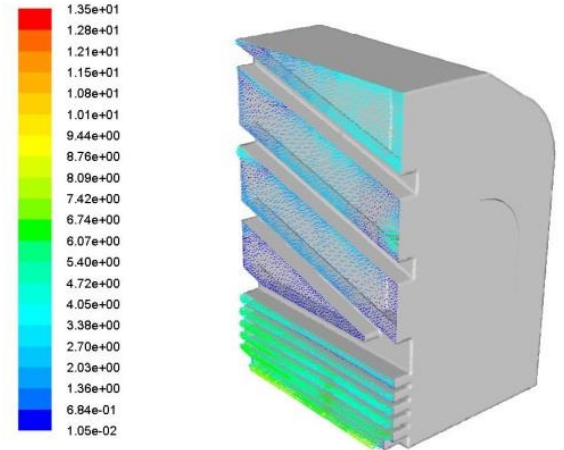

(c)
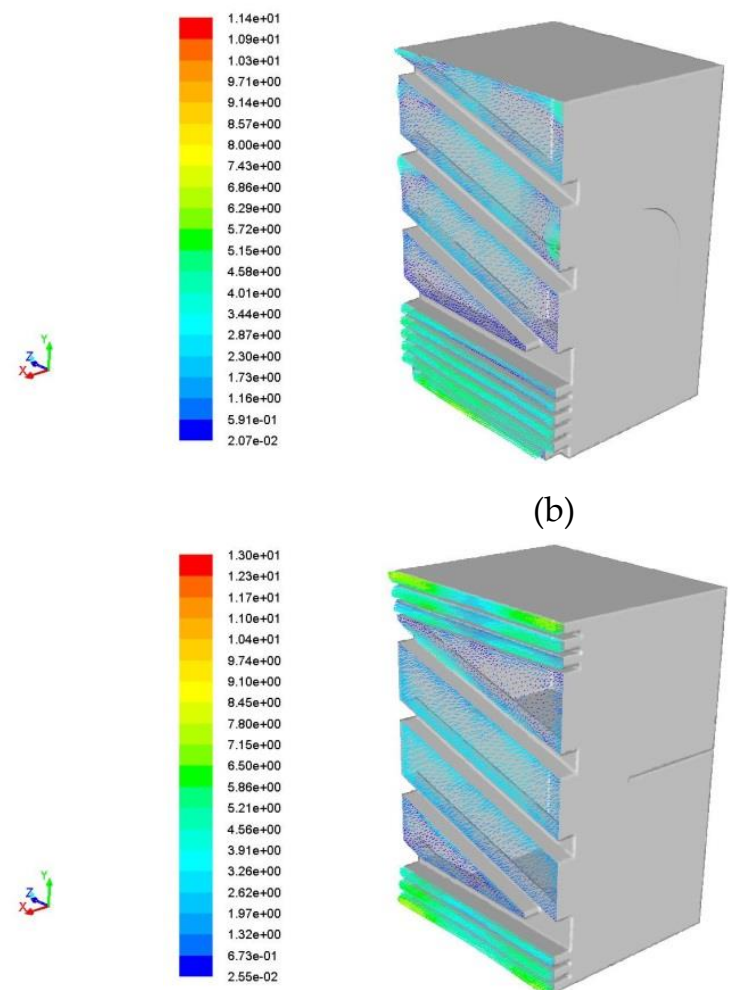

2.55e-02 (b)
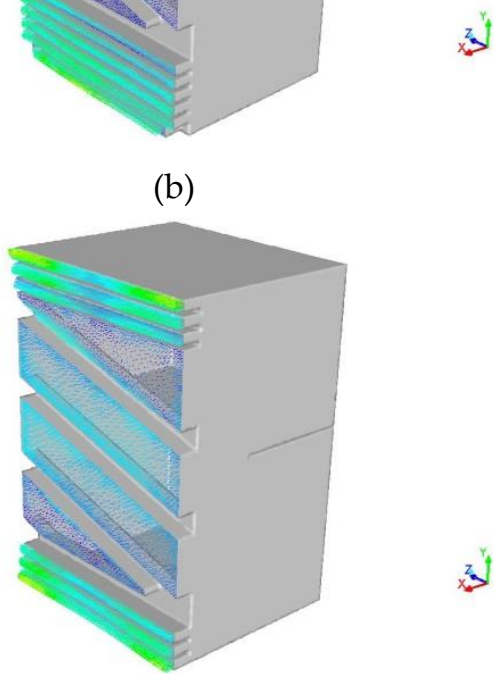

(d)

Figure 10. Inlet and outlet velocity vector fields [m/s] (a) without guide vanes, (b) with one stream guide vane, (c) with two stream guide vanes, $(d)$ with stream separation.

Velocity vector fields are shown in Figure 9, while inlet and outlet velocity vector fields are presented in Figure 10.

As a result of the simulation, it was found that the best solution in terms of noise emission as well as the occurring flow phenomena was obtained for variant $\mathrm{d}$ ) - the variant with the stream separation. The maximum values of the noise level for this variant were estimated at $57 \mathrm{~dB}$. 


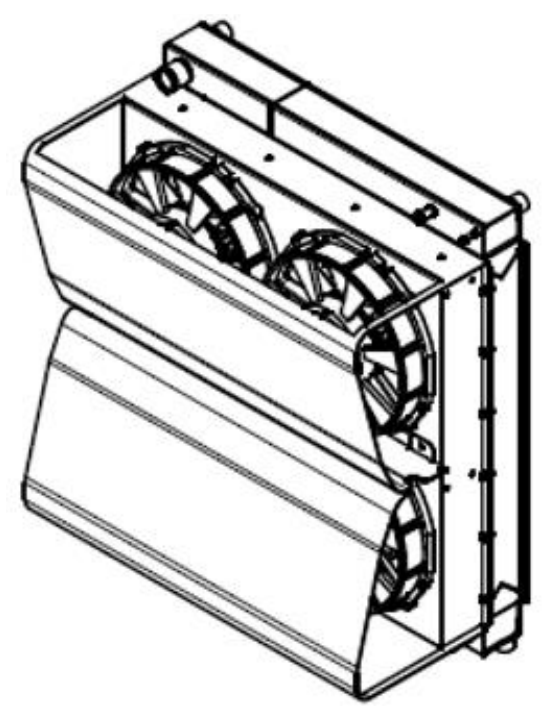

Figure 11. Selected radiator geometry

In the next stage, empirical verification of the numerical model was conducted. A prototype device was made according to the geometric model selected as a result of simulation tests. The experimental tests were conducted in the field conditions at the Military Institute of Armoured and Automotive Technology. Figure 12 shows the view of the test stand during the study implementation.

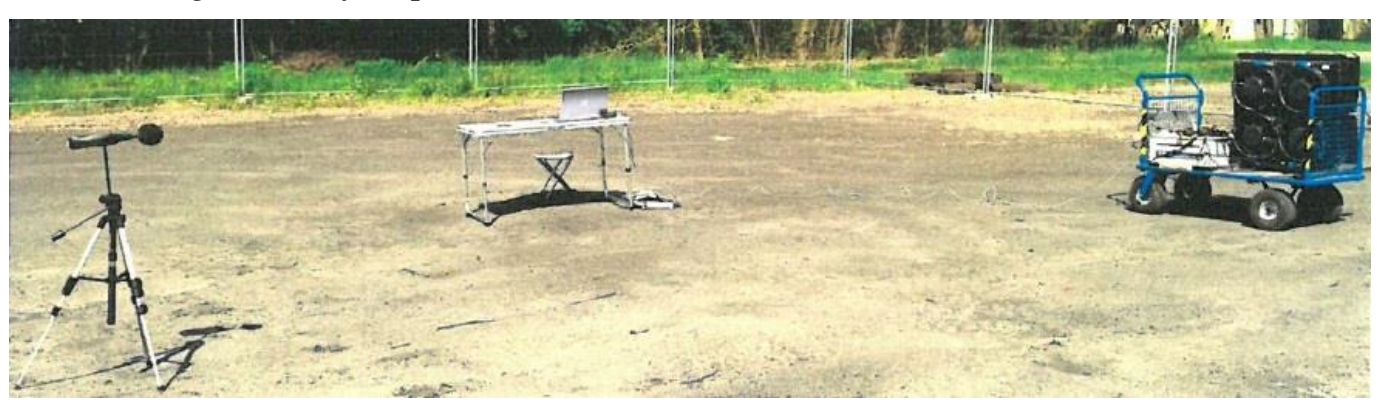

Figure 12. The view of the test stand during the performance of acoustic pressure tests of the radiator.

Comparative tests of the base solution (Figure 1) and the solution resulting from the numerical tests were performed (Figure 11). 


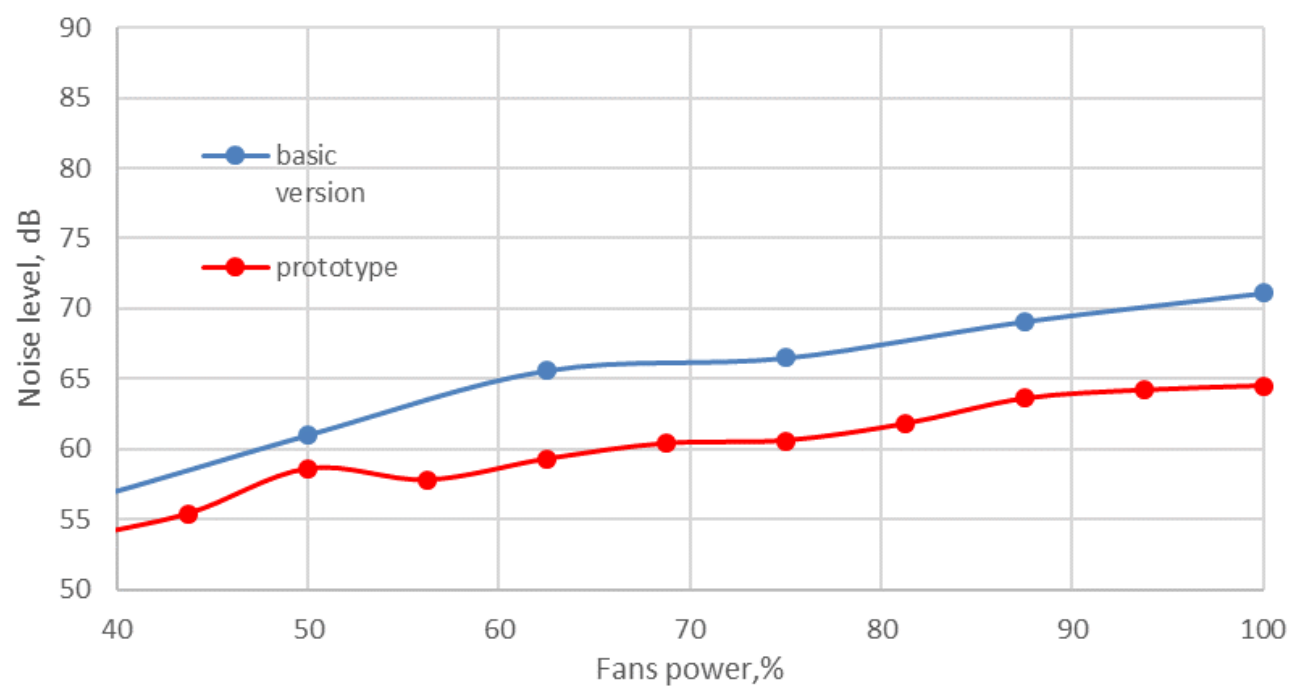

Figure 12. Results of noise level measurements - comparison of the base and prototype versions (developed on the basis of numerical analysis)

The accuracy of the calculation model was found to be very good - under simulation conditions, the maximum noise level was estimated at $57 \mathrm{~dB}$, under measurement conditions for the same operating point ( $50 \%$ of fan power) at $59 \mathrm{~dB}$.

Measurements were then carried out to determine the prototype's power requirement in laboratory and field conditions according to the measurement methods described in Chapter 3.

Figure 13 shows the results of laboratory tests, while Figure 14 shows the results of field tests.

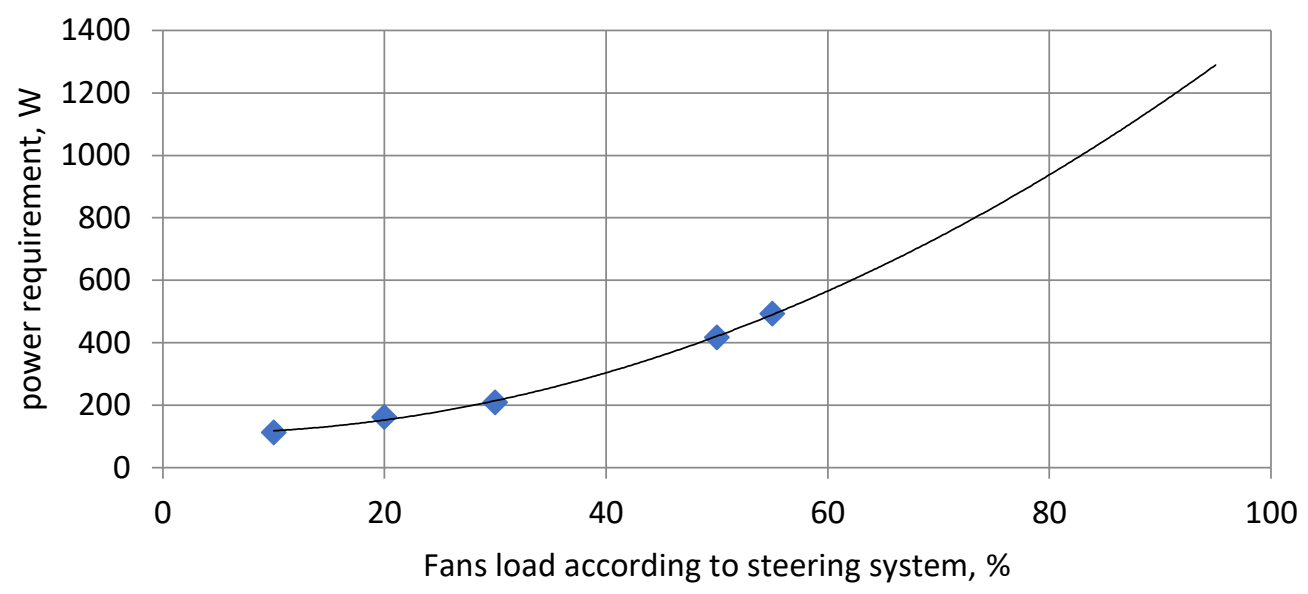

Figure 14. Cooling fan power consumption depending on the $\%$ of the load defined by the control system in laboratory conditions

The results of the power measurement in field conditions on the constructed stand are shown in Figure 14. 


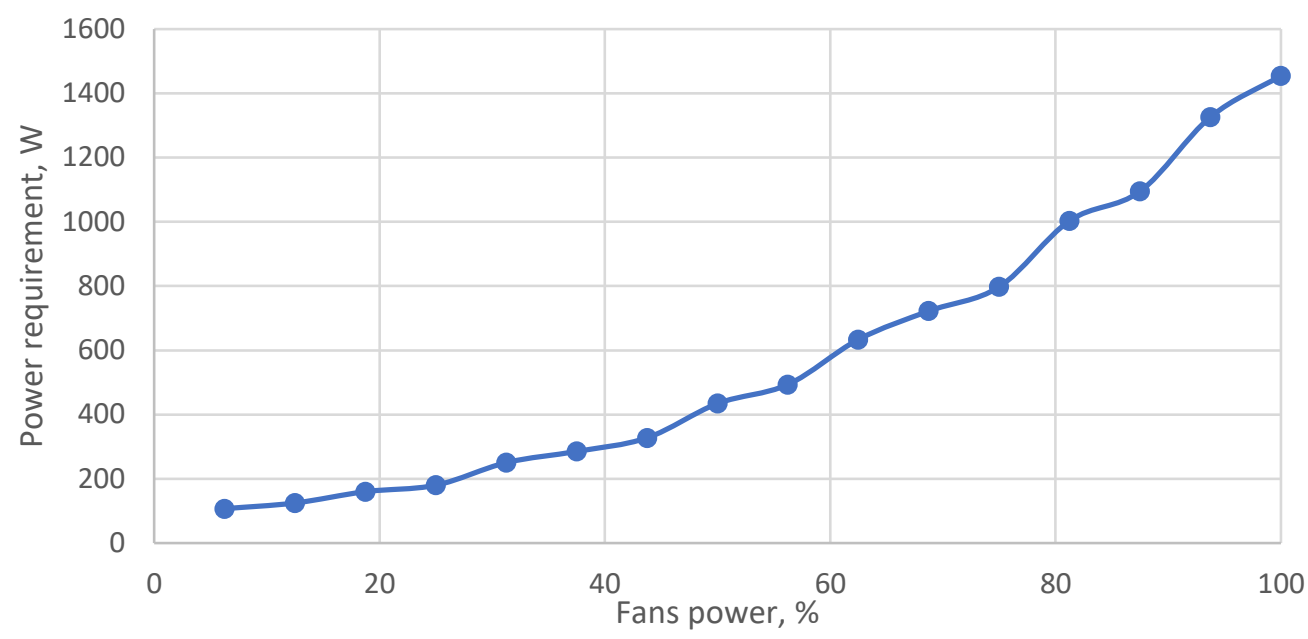

Figure 14. Measurement of power requirement in field conditions

It was found that the determined characteristics were convergent and that there were no changes in the electric power requirement of the device after the performed optimization.

\section{Conclusions}

1. Application of the CFD RANS method of the two-equation $\mathrm{k}-\varepsilon$ turbulence model with the heat transfer and acoustic model as a tool to optimize the vehicle's cooling system in terms of noise emission is a tool adequate for the intended purpose. Consistency of the simulation results and test results of the real object was demonstrated, i.e. $57 \mathrm{~dB}$ as a result of the simulation and $59 \mathrm{~dB}$ on the basis of field tests.

2. The division of the stream of flowing air by the cooling unit caused a decrease in the maximum velocity values, resulting in a decrease in the resistance of the flowing stream.

3. Reducing the pressure level and obtaining an even flow through the radiators allowed for a higher cooling efficiency while maintaining a comparable level of electric power.

Acknowledgements: The research was conducted as part of a project co-financed by the National Centre for Research and Development entitled: "Innowacyjna generacja ultralekkich modułów chłodzących o zminimalizowanym poziomie emisji hałasu, zapotrzebowania na energię elektryczna, poprzez zaimplementowany nowy system bieżącego monitorowania parametrów pracy, przeznaczony do nowych pojazdów z napędem elektrycznym w tym zasilanych ogniwami wodorowymi" [Innovative generation of ultra-light cooling modules with minimized noise emission, electricity demand, through the implemented new system of ongoing monitoring of operating parameters, intended for new electric vehicles, including those powered by hydrogen cells], project no: POIR.01.01.01-00-0147/17

\section{References}

1. Sroka Z. J., Sadlak Z., Thermal activation of the combustion chamber of a reciprocating internal combustion engine. Journal of Thermal Science. 2018, vol. 27, nr 5, s. 449-455, https://doi.org/10.1007/s11630-018-1039-7

2. Shashank Arora; Selection of thermal management system for modular battery packs of electric vehicles: A review of existing and emerging technologies, Journal of Power Sources 400 (2018) 621-640, https://doi.org/10.1016/j.jpowsour.2018.08.020

3. Jaewan Kim, Jinwoo Oh, Hoseong Lee, Review on battery thermal management system for electric vehicles, Applied Thermal Engineering 149 (2019) 192-212, https://doi.org/10.1016/j.applthermaleng.2018.12.020 
4. Mengyao Lu, Xuelai Zhang, Jun Ji, Xiaofeng Xu, Yongyichuan Zhang; Research progress on power battery cooling technology for electric vehicles, Journal of Energy Storage 27 (2020) 101155, https://doi.org/10.1016/j.est.2019.101155

5. A.A. Hakeem Akinlabi, Davut Solyali: Configuration, design, and optimization of air-cooled battery thermal management system for electric vehicles: A review, Renewable and Sustainable Energy Reviews 125 (2020) 109815, https://doi.org/10.1016/j.rser.2020.109815

6. Jing Wu, Guoliang Zhou, Mingyu Wang A comprehensive assessment of refrigerants for cabin heating and cooling on electric vehicles, Applied Thermal Engineering 174 (2020) 115258, https://doi.org/10.1016/j.applthermaleng.2020.115258

7. Ming Shen, Qing Gao, Structure design and effect analysis on refrigerant cooling enhancement of battery thermal management system for electric vehicles, Journal of Energy Storage 32 (2020) 101940, https://doi.org/10.1016/j.est.2020.101940

8. DONG Junqi, WANG Yibiao, JIA Shiwei, ZHANG Xianhui, HUANG Linjie: Experimental Study of R744 Heat Pump System for Electric Vehicle Application, Applied Thermal Engineering (2020), https://doi.org/10.1016/j.applthermaleng.2020.116191

9. Yibiao WANG , Junqi DONG, Shiwei JIA , Linjie HUANG, Experimental Comparison of R744 and R134a Heat Pump Systems for Electric Vehicle Application, International, Journal of Refrigeration (2020), doi: https://doi.org/10.1016/j.ijrefrig.2020.10.026

10. Yiyu Chen, Huiming Zou, Junqi Dong, Jiang Wu, Hongbo Xu , Changqing Tian, Experimental investigation on the heating performance of a CO2 heat pump system with intermediate cooling for electric vehicles, Applied Thermal Engineering 182 (2021) 116039

11. Changsheng Qiu, Wankai Shi, Comprehensive modeling for optimized design of a thermoelectric cooler with non-constant cross-section: Theoretical considerations, Applied Thermal Engineering 176 (2020) 115384, https://doi.org/10.1016/j.applthermaleng.2020.115384

12. Zawiślak M. Method of designing and modernising machines and flow systems using Computational Fluid Mechanics, 2017, Wydawnictwo Politechniki Poznańskiej

13. Ruiqing Shen, Zeren Jiao, Trent Parker, Yue Sun, Qingsheng Wang: Recent application of Computational Fluid Dynamics (CFD) in process safety and loss prevention: A review, Journal of Loss Prevention in the Process Industries 67 (2020) 104252, https://doi.org/10.1016/j.jlp.2020.104252

14. Haowen Yuan, Hongchun Su, Li Wangc, Chun Yuan, Zhebin Zhang: Numerical analysis on airflow and thermal field in quiet power vehicle compartment, Procedia Engineering 174 (2017 ) 571 - 578 doi: 10.1016/j.proeng.2017.01.189

15. Chunhui Zhang, Mesbah Uddin, Austin Clay Robinson, Lee Foster, Full vehicle CFD investigations on the influence of frontend configuration on radiator performance and cooling drag, Applied Thermal Engineering 130 (2018) 1328-1340, https://doi.org/10.1016/j.applthermaleng.2017.11.086

16. Hamidreza Behia, Danial Karimia, Mohammadreza Behic, Morteza Ghanbarpourd, Joris Jaguemonta, Mohsen Akbarzadeh Sokkeha, Foad Heidari Gandomana, Maitane Berecibara, Joeri Van Mierlo, A new concept of thermal management system in Li-ion battery using air cooling and heat pipe for electric vehicles, Applied Thermal Engineering 174 (2020) 115280, https://doi.org/10.1016/j.applthermaleng.2020.115280

17. Kawtar Benabdelaziz, Badreddine Lebrouhi, Anas Maftah, Mohammed Maaroufi: Novel external cooling solution for electric vehicle battery pack Energy Reports 6 (2020) 262-272, https://doi.org/10.1016/j.egyr.2019.10.043

18. Ruoyang Yuan, Tom Fletcher, Ahmed Ahmedov, Nikolaos Kalantzis, Antonios Pezouvanis, Nilabza Dutta, Andrew Watson, Kambiz Ebrahimi: Modelling and Co-simulation of hybrid vehicles: A thermal management perspective: Applied Thermal Engineering 180 (2020) 115883, https://doi.org/10.1016/j.applthermaleng.2020.115883 